X-ray source brightness comparison:

Rigaku rotating anode source vs. Kevex microfocus tube

J. A. Koch, E. Dewald, B. Kozioziemski

March 18, 2010 
This document was prepared as an account of work sponsored by an agency of the United States government. Neither the United States government nor Lawrence Livermore National Security, LLC, nor any of their employees makes any warranty, expressed or implied, or assumes any legal liability or responsibility for the accuracy, completeness, or usefulness of any information, apparatus, product, or process disclosed, or represents that its use would not infringe privately owned rights. Reference herein to any specific commercial product, process, or service by trade name, trademark, manufacturer, or otherwise does not necessarily constitute or imply its endorsement, recommendation, or favoring by the United States government or Lawrence Livermore National Security, LLC. The views and opinions of authors expressed herein do not necessarily state or reflect those of the United States government or Lawrence Livermore National Security, LLC, and shall not be used for advertising or product endorsement purposes.

This work performed under the auspices of the U.S. Department of Energy by Lawrence Livermore National Laboratory under Contract DE-AC52-07NA27344. 
March 17, 2010

\title{
X-ray source brightness comparison: Rigaku rotating anode source vs. Kevex microfocus tube
}

\author{
Jeffrey A. Koch, Eduard Dewald, Bernie Kozioziemski
}

\section{Introduction}

In 2007, we began to explore alternative $x$-ray sources for application to refraction-enhanced (phase contrast) $x$-ray radiography of cryogenic NIF ignition capsules containing frozen deuterium-tritium (D-T) ice layers [1]. These radiographs are currently obtained using Kevex microfocus tubes [2] as backlights, and for these sources the x-ray source size is approximately $5 \mu \mathrm{m}$. As part of this exploration, we obtained refraction-enhanced radiographs of empty plastic capsules using the Janus laser facility at LLNL, demonstrating that even large $(\sim 100 \mu \mathrm{m})$ sources can be utilized in refraction-enhanced radiography provided the source/sample distance is sufficiently large, and provided the final x-ray detector has sufficient spatial resolution $[3,4]$. Essentially, in the current geometry, we rely on a small source to provide spatial resolution and on the source/sample distance to provide refraction contrast, but an equally useful alternative geometry is to use a large source and rely on fine detector spatial resolution to provide spatial resolution and on the sample/detector distance to provide refraction contrast.

Refraction-enhanced radiography is particularly important for quantifying the dimensions of grain-boundary grooves that are often present in the ice layers [5]. For a groove of depth A, width w, radiographed with a source/object distance of $p$ and an object/detector distance of $q$ and a source wavelength $\lambda$, the following inequality must hold if the groove is to be detected:

$$
\text { Contrast } \propto \frac{A \lambda^{2}}{w^{2}} \frac{p q}{(p+q)}>\frac{1}{S / N} \approx \frac{1}{\sqrt{N}}
$$

where $\mathrm{S} / \mathrm{N}$ is the signal-to-noise ratio and $\mathrm{N}$ is the detected number of photons per resolution element. Typically, $w$ is roughly constant [5], and grooves have variable depths. We can write the number of photons per resolution element as:

$$
N \propto I \sigma^{4} \frac{(p+q)^{2}}{p^{2} q^{2}}
$$

where $\sigma$ is the spatial resolution and I is the source intensity is photon per unit area. Combining (1) and (2), we see that in order to detect a groove with minimum depth $\mathrm{A}_{\text {minimum, }}$ the following scaling holds: 


$$
A_{\text {min imum }} \propto \frac{w^{2}}{\lambda^{2} \sigma^{2} \sqrt{I \tau}}
$$

We see that the minimum detectable groove depth scales with $\mathrm{w}$, which is roughly constant for all grooves; with $1 / \lambda^{2}$; with $1 / \sigma^{2}$, which is not a free parameter because we require spatial resolution at the sample of $\sim 5 \mu \mathrm{m}$; and with $1 / \operatorname{sqrt}(\mathrm{I} \tau)$, where $\tau$ is the integration time. Therefore, the path to improved radiography images moves to longer wavelengths, brighter sources, and longer integration times, regardless of the size of the source.

We recently tested a powerful rotating anode source, a Rigaku 007HF [6], for source brightness in experiments at Rigaku's Houston facility, and compared the results to what we obtain from our current Kevex sources. The Rigaku source has promise to improve the quality of our refraction-enhanced radiographs, by having high brightness and longer wavelengths despite having a relatively large source diameter. We find a net improvement of a factor of 3.2 in the metric $\lambda^{2} \operatorname{sqrt}(\mathrm{I})$, equivalent to taking exposures with the Kevex source that are 10.4 times longer than current exposure times of $\sim 300$ seconds. Equivalently, with a fixed exposure time of 300 seconds, the Rigaku source would allow grooves that are 0.31 times as deep to be detected with the same fidelity.

\section{Rigaku Tests}

In September 2009, we arranged a demonstration test of the Rigaku 007HF at Rigaku's Houston facility, using their source and an Xradia detector [7] that we shipped to Houston from LLNL. This detector had been pre-calibrated at NSTec's Livermore facility for optical CCD counts per incident photon, and the results are summarized in Table 1 below.

\begin{tabular}{|c|c|c|}
\hline Anode, filter & Energy, eV & $\begin{array}{c}\text { Counts per } \\
\text { photon }\end{array}$ \\
\hline Ag, no filter & 2120 & 0.78 \\
\hline Ti, no filter & 4510 & 2.08 \\
\hline Ti, Ti 25 micron & 4620 & 2.18 \\
\hline Cr, Cr 25 micron & 5700 & 3.17 \\
\hline Fe, Fe 25 micron & 6650 & 4.01 \\
\hline Cu, Ni 25 micron & 8470 & 8.2 \\
\hline
\end{tabular}

Table 1: NSTec calibration results for the Xradia detector. 
The source ran a $\mathrm{Cr}$ anode, emitting principally $5.4 \mathrm{keV}$ radiation. Operating power was 870 Watts, and the source/detector distance was $2372 \mathrm{~mm}$. $275 \mathrm{~mm}$ of this distance was through an air path, and the total filtration was 17.874 mils Be and 2 mils kapton $\left(\mathrm{C}_{22} \mathrm{H}_{10} \mathrm{~N}_{2} \mathrm{O}_{5}, 1.43 \mathrm{~g} / \mathrm{cm}^{3}\right)$. The source size is 70 $\mu \mathrm{m}$. A schematic of the test geometry is shown in Figure 1 below.

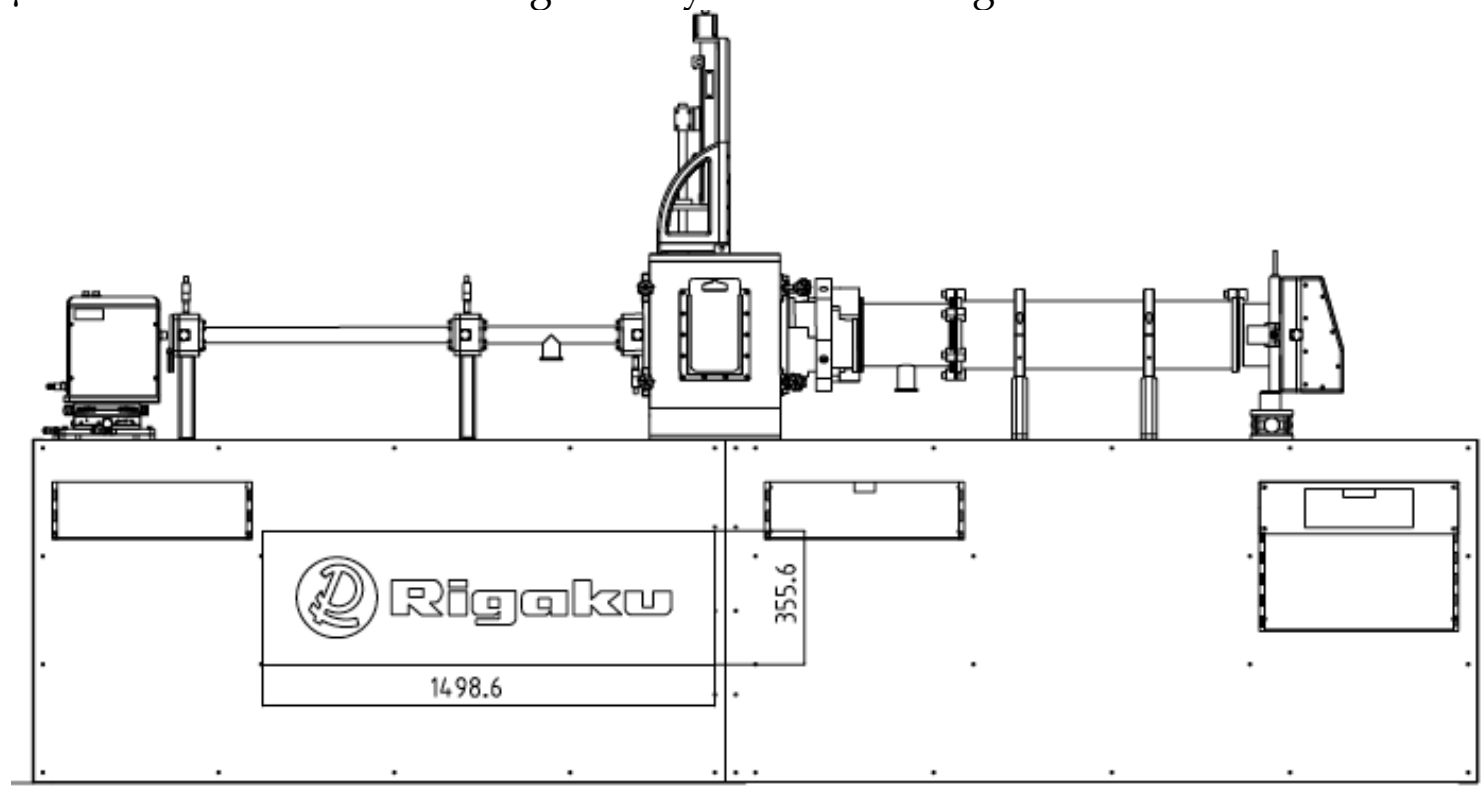

Figure 1: Test geometry at Rigaku. The $\mathrm{x}$-ray source is on the far left emitting $\mathrm{x}$-rays through a collimating hole, and the x-ray detector is on the far right.

After turning on the source, we acquired exposures for fixed lengths of time, and then acquired background exposures with the source off for the same fixed lengths of time. Subtracting the background exposure provides a map of quasi-uniform counts that can be related to the photon flux through Table 1.

\section{Kevex Tests}

We performed essentially identical tests with the Kevex source in the B298 cryogenic target laboratory, which primarily emits $8.5 \mathrm{keV}$ radiation. The source ran a Ta anode, principally emitting $8.5 \mathrm{keV}$ radiation. The source/detector distance was $810 \mathrm{~mm}$, and this path was entirely in air. Total filtration was 4.9 mils of Be, and the source size was $5 \mu \mathrm{m}$. We again acquired both exposures and background images, and subtracting the background exposure provides a map of quasi-uniform counts that can be related to the $8.5 \mathrm{keV}$ photon flux through Table 1.

\section{Results}

The tabulated results are show in Table 2 below. 


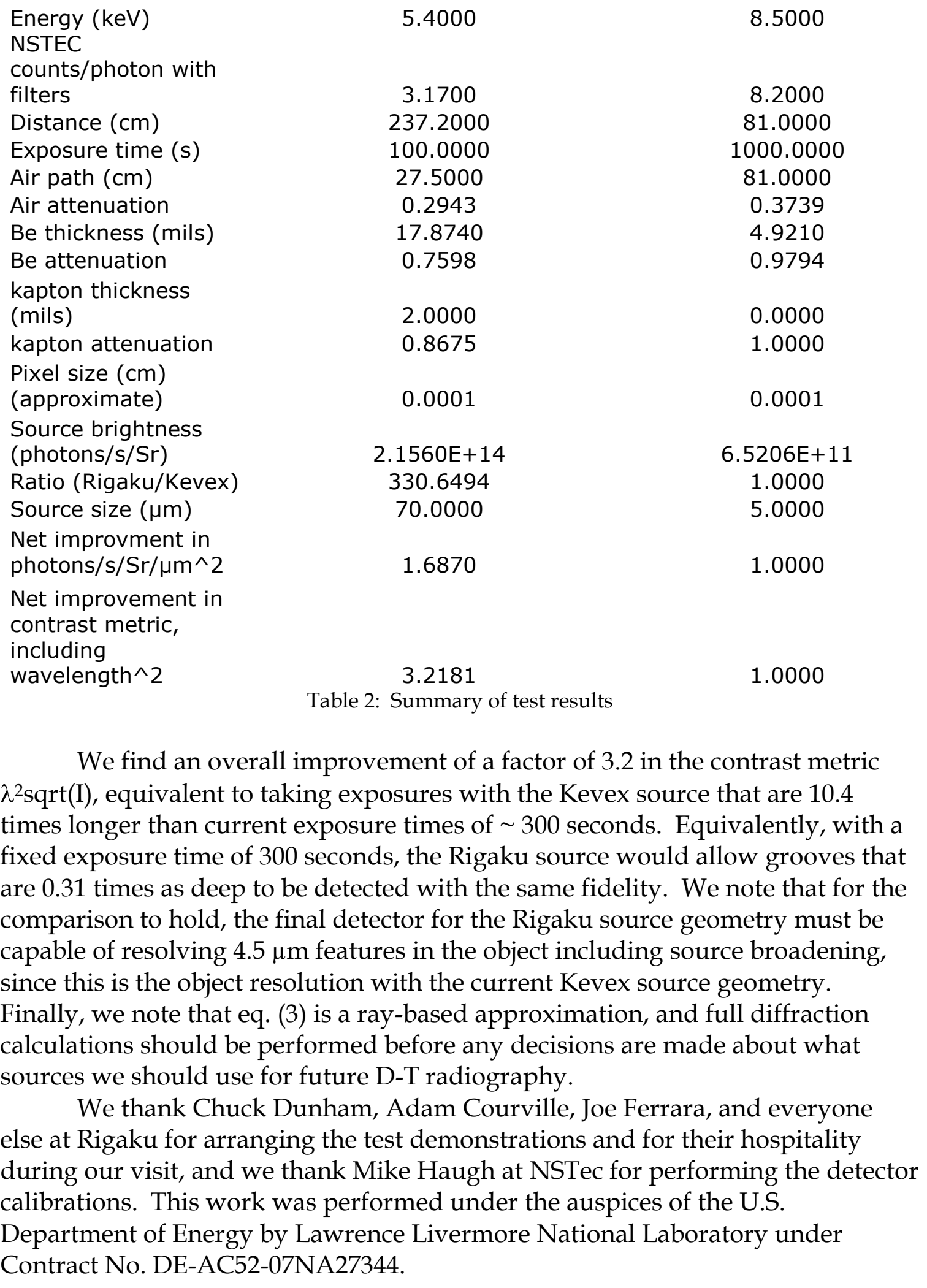

\section{References}


[1] Jeffrey A. Koch, Eduard Dewald, Nobuhiko Izumi, Bernie Kozioziemski, Otto Landen, Craig Siders, "Pulsed laser-based x-ray sources for rapid-cool DT layer characterization", Internal Memo UCRL-TR-234487 (2007).

[2] Thermo Scientific model PXS927EA-LV, http://www.thermo.com/.

[3] N. Izumi, E. Dewald, B. Kozioziemski, O. L. Landen, J. A. Koch,

"Development of a laser-produced plasma x-ray source for phase-contrast

radiography of D-T ice layers", Fusion Science and Technology 55, 253 (2009).

[4] Jeffrey A. Koch, Otto L. Landen, Bernard J. Kozioziemski, Nobuhiko Izumi, Eduard L. Dewald, Jay D. Salmonson, Bruce A. Hammel, "Refraction-enhanced xray radiography for inertial confinement fusion and laser-produced plasma applications", Journal of Applied Physics 105, 113112 (2009).

[5] A. Chernov, B. J. Kozioziemski, J. A. Koch, L. J. Anderson, M. A. Johnson, A. V. Hamza, S. O. Kucheyev, J. B. Lugten, E. A. Mapoles, J. D. Moody, J. D.

Salmonson, J. D. Sater, Applied Physics Letters 94, 064105 (2009)

[6] http:// www.rigaku.com/

[7] http://xradia.com/ 